\author{
Economics Working Paper Series
}

2017/022

\title{
Maternal Employment and Child Outcomes: Evidence from the Irish Marriage Bar
}

\author{
Irene Mosca, Vincent O’Sullivan and Robert E Wright
}

The Department of Economics

Lancaster University Management School

Lancaster LA1 4YX

UK

(C) Authors

All rights reserved. Short sections of text, not to exceed two paragraphs, may be quoted without explicit permission, provided that full acknowledgement is given. 


\title{
Maternal Employment and Child Outcomes: Evidence from the Irish Marriage Bar
}

\author{
by \\ Irene Mosca $(* *)$ \\ The Irish Longitudinal Study on Ageing (TILDA) \\ Trinity College Dublin, Ireland \\ Vincent O’Sullivan \\ Department of Economics \\ Lancaster University, UK \\ Robert E Wright \\ Department of Economics \\ University of Strathclyde, Glasgow, UK
}

September 2017

\begin{abstract}
This paper empirically investigates the relationship between maternal employment and child outcomes using micro-data collected in the third wave of The Irish Longitudinal Study on Ageing. A novel source of exogenous variation in the employment decisions of women is used to investigate this relationship. Between the 1920s and the 1970s, women working in certain sectors or in certain jobs were required to leave paid employment upon getting married in Ireland. The majority of women affected by this "Marriage Bar" then became mothers and never returned to work, or returned only after several years. Regression analysis is used to compare the educational attainment of the children of mothers who were required to leave employment on marriage because of the Marriage Bar to the educational attainment of the children of mothers who were not required to do so. It is found that the children of mothers affected by the Marriage Bar have a much higher probability of completing university education than the children of mothers who were not. The difference is around seven percentage points. This is a sizeable effect when compared to the observation that about $40 \%$ of the children in the sample completed university education. This effect is found to be robust to alternative specifications that include variables aimed at controlling for differences in maternal occupation and personality traits and differences in paternal education.
\end{abstract}

Keys words: $\quad$ marriage, mother, employment, child, education

JEL classification: J12, J16, J20

(*) Financial support provided by the Irish Government, the Atlantic Philanthropies and Irish Life plc is gratefully acknowledged.

(**) Author to whom all correspondence should be addressed: The Irish Longitudinal Study of Ageing (TILDA), Lincoln Gate, Trinity College, Dublin 2, Republic of Ireland. Tel: +353 1896 2509. E-mail: MOSCAI@tcd.ie 


\section{Introduction}

It is difficult to establish a priori whether maternal employment has a positive or negative impact on child development. Maternal employment can have a negative effect on child development for two main reasons. First, as time constraints exist, the children of working mothers spend on average less time in maternal care than the children of non-working mothers. Spending less time in maternal care can be detrimental to child development if non-maternal childcare arrangements are of inferior quality or are a poor substitute of maternal care. Second, maternal employment can indirectly negatively affect the quality of maternal care through its effect on the mother's mental and physical health. For example, mothers who work long hours can be subject to emotional distress, and this can in turn have a negative effect on the quality of their childcare.

On the other hand, maternal employment can have a positive effect on child development also for two reasons. First, maternal employment increases family income. Increased family income can be used to purchase child development inputs such as books and educational trips and possibly to purchase high-quality childcare. Increased family income can also be used to purchase domestic services such as cleaning and home maintenance, which in turn can have a positive effect on the quality of the mother's childcare by making available more of the mother's time for childparent interaction. Second, the indirect effect of maternal employment on child development through mother's health, can also be positive. For example, mothers who derive satisfaction from work might be in better mental health, and this can in turn have a positive effect on the quality of their childcare.

The direction of the effect of maternal employment on child development can only be established empirically. Therefore, it is not surprising that a large empirical 
literature has evolved (somewhat independently) in the fields of economics, psychology and sociology. The empirical studies to date have used a wide array of what can be termed "child outcomes" to measure child development. These include child cognitive development test scores, school grades and educational attainment. As discussed in the next section, there is little consensus in the literature on either the direction of association or the relative importance of maternal employment on child outcomes. While most of these studies assume that the causal direction is from maternal employment to child outcomes, a small number of studies consider the opposite causal direction. More specifically, child outcomes may impact on the employment decisions of mothers. For example, it is not unreasonable to believe that if a child is doing poorly in school, a mother may reduce the amount of work she is doing, or stop working completely, in order to spend more time with the child in an attempt to improve the child's performance in school.

This paper adds to the body of research that investigates the effects of maternal employment on child outcomes using data from Ireland. We believe our methodological approach is both novel and in several ways an improvement on previous studies. Section 2 critically reviews the research to date that has examined the relationship between maternal employment and child outcomes in countries other than Ireland. The two main aims of this section are to evaluate the strengths and weaknesses of previous studies and to highlight the key contributions of this paper. Section 3 is an empirical investigation of this relationship that addresses some of the weaknesses of previous studies, using data collected in The Irish Longitudinal Study on Ageing (TILDA).

Between the 1920s and the 1970s, women working in certain sectors or in certain jobs were required to leave paid employment upon getting married in Ireland. The majority of women affected by this “Marriage Bar” then became mothers and never 
returned to work, or returned only after several years. As the Marriage Bar was abolished only in the 1970s, many of the women affected are still alive and are among the TILDA respondents. We argue that a comparison of the two groups of mothers, those affected by and those not affected by the Marriage Bar, forms a good test of the relationship between maternal employment and child outcomes. Empirical results are reported in Section 4. Regression analysis suggests that the children of mothers who left employment because of the Marriage Bar have a considerably higher probability of completing university education compared to the children of mothers not affected by the Marriage Bar, even after controlling for other factors. This results is found to be robust to alternative empirical specifications. Conclusions follow in Section 5.

\section{Previous Research}

Assessing the causal effect of maternal employment on child outcomes is complicated by two empirical issues. The first issue is unobserved heterogeneity, which arises because of the presence of non-measured factors that likely affect both maternal employment and child outcomes. Examples of such factors are motivation, productivity, ability and personality traits. To illustrate, assume that mothers who work have higher ability than mothers who do not. If higher ability is a family trait that is passed along to children, then the children of high ability mothers will likely have better outcomes. If ability is unobserved, then maternal employment may be spuriously related to child outcomes. In other words, the relationship may not be "causal". Similarly, mothers who are more productive in the labour market may also be more productive in their parenting. If productivity is unobserved, the econometric estimates on the effects of maternal employment on child outcomes are likely to be biased. 
The second empirical issue is the direction of causation. It seems reasonable to assume that the causal direction is from maternal employment to child outcomes. However, it is also possible that child outcomes affect maternal employment if there is a feedback mechanism between child outcomes and maternal employment. For example, if a child is not achieving an expected outcome (such as doing well in school), a mother might choose to leave employment and spend the newly available time with the child attempting to improve the child's performance in school. Another example is given by a mother who compares the outcomes of her children at a given point in time, such as after the first year in school. If a younger child is doing less well than an older child did, she might choose to leave employment and spend the newly available time with the younger child.

Different approaches have been employed to overcome the empirical problems created by unobserved heterogeneity and reverse causation. One group of studies employs what can be termed “quasi-natural experimental” designs, which are created by changes in the rules and regulations relating to maternity leave. These studies use administrative datasets to track the educational performance of children born before or after the date when maternity leave periods were increased. As a group, these studies find very mixed results. Two studies using Norwegian data find positive effects of maternity leave period increases on child outcomes (Carneiro et al, 2011; Bettinger et al., 2014). The findings of two studies using Swedish and Austrian data suggest that the effect of maternity leave period increases is highly dependent on the education level of mothers (Liu and Skans 2010; Danzer and Lavy 2016). Liu and Skans (2010) find that an expansion in maternity leave periods led to improved test scores and grades at age sixteen for children of highly educated mothers but not for children of lowly educated mothers. Danzer and Lavy (2016) find a positive effect of maternity leave period 
increases for highly educated mothers of boys and a negative effect for lowly educated mothers of boys. Four studies using Canadian, German, Danish and Norwegian data find no effects of maternity leave period increases on child outcomes (Baker and Milligan 2010 and 2015; Dustmann and Schonberg 2012; Rasmussen 2010; Dahl et al. 2016).

These mixed results are not surprising because, as with all quasi-natural experimental designs, the results have to be interpreted in the institutional context of the country and time period in focus. For example, one needs to be aware of the generosity of the existing maternity leave system before the expansion, the nature of the expansion in terms of duration and financial generosity, whether the alternative to maternal care is formal or informal care, and, if the alternative care is formal, the costs involved. In addition, the studies based on this methodology assume that mothers who give birth before and after the expansions of maternity leave have full knowledge of the welfare, maternity leave and tax systems and are rational agents.

A second group of studies use data from social surveys, where detailed fertility and employment histories are collected. With this type of data, it is possible to "map" maternal work history information onto child outcomes. Different empirical strategies have been used to control for systematic differences between working and non-working mothers. Some studies include a very large number of exogenous maternal background characteristics (for example, Baum 2003; Berger et al. 2002; and Ruhm 2004 and 2008). Other studies investigate differences in outcomes of sibling pairs, whose mother decided to work when one sibling was born but not when the other was born. With this approach, mother-specific fixed-effects can be used to help control for time-invariant factors that potentially influence both a mother's employment decisions and their parenting style (Waldfogel et al. 2002; James-Burdumy 2005; Ermisch and Francesconi 
2013 and Schildberg-Hoerisch 2011). It is worth noting that all analyses based on “sibling differences” have to exclude by design single child families. This is a weakness of this approach. One cannot exclude that maternal employment affects single children in a systematically different way than it affects children with brothers and/or sisters. In addition, in most high-income countries, one-child families are now the norm not the exception.

A few studies attempt to address the potential "two-way” relationship between maternal working and child outcomes using time and geographic variation in local labour market conditions as instruments for a maternal employment (Baum 2003; James-Burdumy 2005; Ermisch and Francesconi 2013). The logic behind the choice of local labour market conditions is that different local labour markets are characterised by different frictions, such as different levels of unemployment, and that these, in turn, differentially affect mothers' decisions to participate in the labour market. In the analyses of James-Burdumy (2005) and Baum (2003), these instruments prove to be weak and to lead to very large standard errors in the maternal employment variables in the second stage equations. In addition, while labour markets conditions vary geographically so do other factors that likely impact on employment. Therefore, it is not clear if geographical differences in labour market conditions are capturing the true factors determining labour market decision.

The results using this approach are also mixed. Some support is found for maternal employment during the child's first year of life having a negative impact on child outcomes when children are young (James-Burdumy 2005; Baum 2003; Waldfogel et al. 2002). Other studies find mixed evidence that maternal employment affects child outcomes when children are aged 1-3 years (Waldfogel et al. 2002; Ruhm 2004) or when the children are aged 10-11 years (Ruhm 2008). Only two studies 
consider longer-term child outcomes (Ermisch and Francesconi, 2013; SchildbergHoerisch, 2011). The lack of studies that examine the effect of maternal employment on later-life/longer-term outcomes of children is not surprising since datasets that link together later child outcomes and employment histories of their mothers are rare. What is required is a dataset that collects detailed information about children when they are adults and their parents, ideally with both generations being interviewed independently.

The findings of Ermisch and Francesconi (2013) and Schildberg-Hoerisch (2011) do not agree. Using data from a sample of just over 1,000 children included in the British Household Panel Study (BHPS), Ermisch and Francesconi (2013) examine the effect of maternal employment on the probability of her children obtaining upper secondary-level qualifications. The authors use sibling differences in the timing of maternal employment and instrument maternal employment using local labour market conditions. They find a negative and statistically significant effect of full-time maternal employment (during the first five years of her child's life) on the probability that the child would achieve upper secondary qualifications. They argue that this finding is important for two reasons. First, early parental investments are important in the preschool period and not only in the child's first year of life. Second, early parental investments have an impact on a child's later-life achievements.

Using data from the German Socioeconomic Panel (SOEP) and estimating a sibling difference model, Schildberg-Hoerisch (2011) does not find an effect of maternal employment while the child is less than three years of age on the probability that the child would attend academic-track secondary schooling rather than vocational schooling. She attempts to avoid inconsistent estimates due to reverse causality (i.e. the causal direction is from child outcomes to maternal employment) following two approaches. The first is to exclude disabled children and children with very low ability 
from the analysis. The logic behind this exclusion is that if it is true that mothers condition employment decisions on child ability, then one would expect the mothers of a child with a disability or very low ability to reduce hours of work or to cease work completely to spend more time with the child. In other terms, one would expect that for this group of mothers, the direction of causality is from child ability to maternal employment, and not the other way round. The second is to focus on the effect of maternal employment when children are "young” (less than age three). SchildbergHoerisch (2011) argues that that signals about child ability should still be scarce at such an early age. If it is "too early” for mothers to assess child ability, then it is not plausible to assume that they condition employment decisions on child ability. We argue that whether signals about child ability are "too scarce" between birth and age three is, however, debatable.

It is our view the empirical research to date has not generated convincing evidence about the relative importance of maternal employment on child outcomes. As indicated there are methodological weaknesses with the approaches followed in these studies. We believe that the analysis in this paper improves on these studies in four ways. The first is that we use a novel source of exogenous variation in the employment decisions of women caused by the "Marriage Bar" in Ireland. The Marriage Bar was the legal requirement that women working in certain sectors or jobs leave paid employment on getting married. It was established in the 1920s, a time of high unemployment amongst males, and abolished in the 1970s. Crucially for our research question, the Marriage Bar affected the employment of women, particularly welleducated women, but did not directly affect their parenting ability.

The second is that we focus on later-life child outcomes. More specifically, the outcome is the probability that the child has graduated from university. With the 
exception of Bettinger et al. (2014), the papers that examined the effects of increase in maternity leave periods focus on the impact of maternal employment during the first few years of the child's life. While it is clearly important to understand these short-run impacts, it is more important to understand the longer-run or later-life impact of maternal employment. Of the studies using sibling differences, only Ermisch and Francesconi (2013) and Schildberg-Hoerisch (2011) focus on the probability that the child has graduated from secondary school. Their choice of outcome was mostly driven by the data that they used. However, evidence suggests that university education is a much stronger predictor of labour market and economic success than secondary education. For example, in 2015, just under $85 \%$ of young adults aged 25 to 34 in OECD developed countries had completed secondary education (OECD 2016). This compares to $40 \%$ having completed tertiary education. In 2014, university graduates earned nearly $50 \%$ more than those who had only completed secondary school.

The third is that our analysis of maternal employment is not limited to the first few years of a child's life but is captured over the life-time since most mothers affected by the Marriage Bar never returned to work or returned only after several years. There is no doubt the first few years of life are an important in terms of child development (Lewis and Brooks-Gunn 1979). However, much less is known about the impacts of maternal employment when children are older, such as when they are in primary and secondary school. If there is a sizable impact of maternal employment when their children are older, then policy-makers need to consider introducing policy that allows mothers to have flexible work arrangements beyond the first few years of motherhood.

The fourth is that Ireland is an ideal quasi-natural experimental design to examine the effect of maternal employment on child outcomes. As is discussed below, for the generation of women included in our sample, almost all child bearing occurred 
in marriage and almost all women married. These cultural norms were largely an outcome of the importance of the Catholic Church in Irish society. In addition, most women worked for a period after leaving school. There was no paid maternity leave until 1969 and no employment-protected leave until 1981. There was no statesubsidised childcare until the 1990s. In the 1960s, 1970s and early 1980s, when many of the children of the women in the TILDA sample were born, the alternative to maternal childcare would have been a choice between family and friends or informal paid arrangements. Therefore, many of the factors that confound the relationship between maternal employment and child outcomes in other higher-income countries, are in a sense "held constant" in Ireland.

\section{Method}

\section{Data}

The analysis is based on data from the third wave (2014/2105) of The Irish Longitudinal Study on Ageing (TILDA), a nationally representative sample of community dwelling individuals aged fifty and older resident in Ireland. The survey collects information on the economic, health and social aspects of the respondents' lives. It is modelled closely on the US Health and Retirement Study (HRS), the English Longitudinal Study on Ageing (ELSA) and the Survey of Health, Retirement and Ageing in Europe (SHARE). Data from the third wave of TILDA are used because in this wave, all women who reported that they had worked and married during their lives were asked about the Marriage Bar. More detail about TILDA can be found in Kearney et al. (2011), Whelan and Savva (2013), and Cronin et al. (2013).

The sample is restricted to women born before 1955. This is because women born after 1954 who married before 1973, the year in which the Marriage Bar was 
abolished, would have married before her eighteenth birthday. At that time, it was unusual for women to marry at such a young age. For example, in 1971, only $12 \%$ of marriages involved women aged younger than twenty years old (CSO, 1971). Women who married at such an early age might have behaved differently as a parent relative to women who married at older ages. Furthermore, women who married at such a young age might have done so because they became pregnant. The initial sample of women in the TILDA sample born during or before 1954 consists of 2,642 observations.

The main aim is to compare the educational outcomes of children born to women who were "forced" to leave their job because of the Marriage Bar to the outcomes of children born to women who were not forced to leave a job when they married. As the Marriage Bar could only affect women who worked and married, women who never worked $(n=240)$ and never married $(n=200)$ have to be excluded from the sample. By definition, women who never had children $(n=122)$ have to be excluded from the sample. One might argue that the exclusion of women who never worked, never married or never had children might bias the estimates of the effect of the Marriage Bar. For example, we do not know what the outcomes of the children would have been for mothers who did not engage in paid work but who would have chosen to engage in paid work had the Marriage Bar never existed. Similarly, for women who did not have children but who would have chosen to become mothers had the Marriage Bar never existed, we do not know what the outcomes of their hypothetical children would have been.

Crucially the Marriage Bar, and its abolition, did not appear to have much affect the decision of women to work, marry or have children in a major way. We argue that it is likely that the Marriage Bar did not affect these major decisions because of the legal, social and cultural context of Ireland before the 1980s. We provide evidence in 
support of this statement in Figures 1 to 5. It is important to note that although women born in 1955-1960 are excluded from the empirical analysis of this paper, they are included in Figures 1 to 5 as they serve as an important comparison group for the period after the Marriage Bar was abolished.

First, we argue that the Marriage Bar did not affect the decision to participate in the labour market. Figure 1 shows the percentage of each three-year birth cohort of women born between the early 1900s and 1960 who "ever worked for pay" and "never worked for pay”. Figure 1 shows that younger cohorts — born in the 1950s - were less likely to have never worked for pay than cohorts born during the 1940s. However, there was no significant change or discontinuity in the percentage of women who never worked for pay for the youngest cohorts in the TILDA dataset, born during the second half of the 1950s and who entered the labour force after the abolition of the Marriage Bar, when compared to the cohorts born during the first half of the 1950s.

Second, we argue that the Marriage Bar did not affect the decision to get married. If the Marriage Bar forced more women to choose a career instead of getting married, one would expect to observe a higher percentage of women who never married in Ireland when compared to other countries, and a higher percentage of women who married for cohorts born after the mid-1950s compared to cohorts born before the mid1950s. Figure 2 shows the percentages of "never married" and "ever married", calculated from the TILDA and SHARE surveys, by birth cohort for various countries. Data are presented for Ireland, Austria, Denmark, France, Germany, Greece, the Netherlands, Spain and Sweden. Figure 2 shows that that the percentage of "never married" women in Ireland is similar to that of other European Countries. Furthermore, the marriage rate does not vary by birth cohort. Figure 3 shows the percentage of each three-year birth cohort that never married. For the cohorts born in the late 1950s, the 
percentage who never married is around the same as for slightly older cohorts who would have entered the labour market while the Marriage Bar was still in place.

Third, we argue that the Marriage Bar did not affect the probability of having children. In the time period we are considering, marriage and having children were linked. Only about $12 \%$ of women in the TILDA sample who never married had children, whereas around 95\% of women who married had children. In Ireland, there was a social stigma attached to motherhood outside of marriage. For example, under Irish law until the 1990s, children were classified as either legitimate or illegitimate. Thus, if the Marriage Bar did not affect the probability of marrying, it is likely that it did not affect the probability of having children. Furthermore, when the Marriage Bar was in effect, there was less of an element of choice in fertility than is the situation today. In Ireland, the availability of contraception was legalized in stages from the late 1970s to the early 1990s. Abortion remains illegal except in limited circumstances. Relatively few women in the TILDA sample, around $11 \%$ of the total, never had children. Figure 4 and Figure 5 show that both having any children at all and the number of children, conditional on having any children, has been falling for successive birth cohorts since the 1950s, most likely because younger cohorts have used contraception to control their fertility.

After the exclusion of women who were born after 1954, who never worked, never married and never had children, the sample consists of 2,080 women. A total of 213 women are excluded because of missing information on one or more control variables (described below). Finally, 122 women are excluded as their children were aged less than 25 at the time of the Wave 3 interview. The final sample consists of 1,745 women. In total these women had 6,241 adult (aged 25 and older) children. The average number of adult children per women is 3.6. The information provided by the women in 
the sample about themselves and about their children is used to construct a child-level dataset. The empirical analysis introduced in the next section is based on this childlevel dataset.

\section{Statistical Model}

A reduced-form specification is used to estimate the impact of maternal employment on child outcomes. More specifically:

$\operatorname{Prob}\left(U N I V_{i k}=1\right)=\Phi\left(M B_{k}, X_{k}, Z_{i k,}\right)$

where $\operatorname{Prob}\left(U N I V_{i k}=1\right)$ is the probability that child " $i$ " of mother " $k$ " $(\mathrm{Ni}>N k)$ graduated from university. $M B_{k}$, is a dummy variable coded " 1 " if mother " $k$ " reports leaving work because of the Marriage Bar upon getting married and coded " 0 ” if not. " $X_{k}$ " is a vector of characteristics of the mothers thought to affect the educational attainment of their children. " $Z_{i k}$ " is a vector of characteristics of the children thought to affect their educational attainment. As is discussed below, " $X_{k}$ " and " $Z_{i k}$ " are assumed to be exogenous. $\Phi$ is the standard normal cumulative distribution. A probit model is estimated using maximum likelihood estimation.

\section{Variables}

The Marriage Bar was the legal requirement that women leave certain jobs when they married. The policy existed in different forms from the 1920s until the 1970s in the Republic of Ireland. There were two motivations for the policy. First, there was a belief at the time that a woman's place was in the home. Indeed, Article 41.2 of the Irish Constitution, written in 1936 and still in effect today, reads that "mothers shall not 
be obliged by economic necessity to engage in labour to the neglect of their duties in the home.” Second, given that there was high unemployment in Ireland at the time, the aim of the Marriage Bar was to reduce male unemployment by limiting households to one income earner: “one man, one job”.

The first laws to curb female employment in the Civil Service were introduced in the 1920s. From 1933, married women had to stop working as primary teachers. The Civil Service introduced a comprehensive Marriage Bar in 1956 (Cullen Owens, 2005). Once married, women could not work in the Civil Service, although exceptions were made for women who could prove desertion or who were widowed (Pyle, 1990). Although not legally obliged to do so, many semi-state and private organisations, including banks, utility companies and large manufacturers dismissed women when they married. Private sector employers dismissed women working in primarily clerical and skilled jobs; but, in some cases, they dismissed unskilled workers (Kiely and Leane, 2012, p.91).

The Marriage Bar was repealed because of the demand for equality and the effects of labour shortages on the economy. It was scrapped for primary school teachers in 1958 because the Marriage Bar, along with a declining number of nuns, had caused shortages of trained female teachers. By the 1960s, labour shortages were becoming a macro-economic problem. In 1970, the government established a commission "to examine and report on the status of women in Irish society and to make recommendations on the steps necessary to ensure the participation of women on equal terms and conditions with men” (Commission on the Status of Women, 1972). After the report of the Commission in 1972, the Civil Service repealed the Marriage Bar 1973.

The labour force participation rate of married women doubled from 1971 to 1975, jumping from $7.5 \%$ to $14.5 \%$ (see Pyle, 1990). Since this sharp response was not 
the result of demographic changes, it most likely reflects the termination of the constraint on labour force participation of married women in those occupations closed to them by the Marriage Bar. In 1977, discrimination in employment on the grounds of sex or marital status was made illegal in both the private sector and the public sector. Once the Marriage Bar was removed, more married women worked in Ireland.

Crucially for our purposes, the data from TILDA supports the view that the employment trajectories of women who were affected by the Marriage Bar differed over the life-time from the trajectories of women not affected by the Marriage Bar. Three measures are used to investigate employment trajectories of the two groups of women. Results are presented in Table 1 . The first measure is number of years spent in employment. Row (a) in Table 1 shows that women who were forced to leave their jobs when they married worked 21.1 years over the course of their lives whereas women unaffected by the Marriage Bar worked 26.7 years on average. The 5.6 year difference between the two groups is statistically significant at the $1 \%$ level.

The second measure is proportion of potential working-life span spent in employment. Potential working-life span is defined as age minus age at labour market entry for women younger than sixty-five; and as sixty-five minus age at labour market entry for those older than sixty-five. Row (b) in Table 1 shows that women affected by the Marriage Bar spent about 44\% of their "potential working-life” in employment. This compares to 56\% for women not affected by the Marriage Bar. The $11.7 \%$ point difference between the two groups is statistically significant at the $1 \%$ level. The third measure is number of years elapsed since the last job ended. Row (c) in Table 1 shows that the women affected by the Marriage Bar have not, on average, worked in the past 25 years. For women unaffected by the Marriage Bar, it has been just under 17 years 
since they last worked. The 7.9 year difference between the two groups is statistically significant at the $1 \%$ level.

The variables included in " $X_{k}$ ", the vector of characteristics of the mothers thought to effect the educational attainment of their children, are: year of birth; educational attainment; age at first birth; and number of living children. As set of dummy variables capturing the childhood socioeconomic circumstances are also included based on the woman's self-reporting of childhood conditions before the age of 14. These capture whether she recalls her family being "poor" during her own childhood; whether she recalls being in "fair/poor health" health during her own childhood; whether she recalls there being "at least ten books" in her childhood home; whether she grew up in a "rural area"; her "number of siblings"; whether her own "mother worked"; and whether her "father worked". Educational attainment is measured by the number of years of schooling completed. The variables included in " $Z_{i k}$ ”, the vector of characteristics of the children thought to affect their educational attainment, are age and sex.

\section{Results}

\section{Descriptive Statistics}

Descriptive statistics are presented in Table 2. It is important to note that the outcome variable and child characteristics are presented at child-level $(\mathrm{N}=6,241)$. Maternal characteristics are presented at mother-level $(\mathrm{N}=1,745)$. Focusing first on the outcome variable, the first row of Table 2 shows that $47.1 \%$ of the children of mothers affected by the Marriage Bar completed university compared to only 35.9\% of the children of women unaffected by it. The difference in educational attainment is statistically significant at the $1 \%$ level. 
Turning then to the maternal characteristics, the results of Table 2 show that women affected by the Marriage Bar were, on average, four years older than women unaffected by it. Concerning their own childhood, women affected by the Marriage Bar came from more favourable backgrounds. About 21\% of women unaffected by the Marriage Bar reported their family was relatively poor during their childhood which is considerably different to the $12 \%$ reported by those women not affected by it. The two groups of women reported similar level of poor health during their childhoods (6-7\%). Women affected by the Marriage Bar were about seven percentage points more likely to recall having books in their childhood home. Recollection of books in the childhood home has been shown to be a good indicator of early life conditions and possibly also a good indicator of parental care in early life (Brunello et al., 2017).

Women affected by the Marriage Bar were less likely to report they grew up in rural areas. Perhaps women who grew up in rural areas were less likely to enter public sector jobs where the Marriage Bar was more prevalent because the public sector was centralised in Dublin. Both groups of women grew up in large families, as they reported to have an average of five brothers and/or sisters (even if deceased at the time of interview). The mothers of women not affected by the Marriage Bar (the grandmothers of the children of the TILDA respondents) were more likely to have been working during the woman's childhood. Given that these families were poorer, the greater female employment may have been due to economic necessity rather than choice. However, their fathers (the grandfathers of the children of the TILDA respondents) were equally likely to have been working during the childhoods of the TILDA respondents. Perhaps because of their more favourable family backgrounds, and despite being from an older generation, women affected by the Marriage Bar left school 0.7 of 
a year later than the other women. This difference in years of schooling is statistically significant at the $1 \%$ level.

On average, age at first birth for women affected by the Marriage Bar was 0.6 years later than for women unaffected by it. On average, women affected by the Marriage Bar had four children, which is 0.5 more children than women unaffected by it. Despite their mothers giving birth at an older age, the average year of birth of the children of women affected by the Marriage Bar was three years earlier than that of the other children. As one would expect, there is no statistically significant difference in the gender between the children of both groups of mothers.

\section{Regression Results}

The regression estimates are shown in Table 3. What is reported are the marginal effects. Standard errors clustered at the family level are presented in parentheses. Focusing first on the variable of most interest to us, the results of Table 3 show that the children of women affected by the Marriage Bar were on average 7.9 percentage points more likely to have completed university compared to the children of mothers who were unaffected by the Marriage Bar. The difference is statistically significant at the $1 \%$ level.

Turning then to the controls, the year of birth the mother did not have a statistically significant effect on the probability of her children completing university. In agreement with the work by Brunello (2017), the probability of obtaining a degree was higher for children with a mother who grew up in a home "with books". The number of the mother's siblings had a small negative effect on the outcomes of her own children. The number of siblings of the mother might be an indicator of her economic circumstances when she was growing up. Potentially, the number of her siblings is a 
better measure of economic circumstances than her recollection of whether she grew up in a poor family which does not have a statistically significant effect on whether her children are graduates. Her recollection of her own childhood health, whether she grew up in a rural area and whether her parents worked did not have a significant effect, at the $10 \%$ level, on the outcomes of her children. A mother's level of education affected the education of her children. Each additional year of maternal education raised the probability of her children completing university by five percentage points. This intergenerational return to years of education is statistically significant at the $1 \%$ level.

The age at which the mother first gave birth had a positive effect on her children completing university. The children of women who delayed entering motherhood by an additional year are about 1.2 percentage points more likely to have completed university. The effect of waiting another year to become a mother on children's educational attainment is smaller than the effect of maternal education, but it is also statistically significant at the $1 \%$ level. This positive age effect of delaying motherhood on child educational attainment could reflect greater maturity and readiness for motherhood at older ages. The number of children the woman had, has a negative effect on the probability of a child completing university. The year of birth of the now adult child has a positive effect on the probability of them attaining a degree. There has been an upward trend in educational attainment in Ireland (see Denny 2014 for further discussion). Female children were about 6.4 percentage points more likely to have completed university.

\section{Robustness Checks}

The results of Table 3 suggest that the children of mothers affected by the Marriage Bar were about 7.9 percentage points more likely to have completed 
university than the children of women unaffected by the Marriage Bar. This is a sizable difference. In an attempt to assess the robustness of this finding, regressions were fit based on alternative specifications. As explained above, and illustrated in Table 2, the Marriage Bar primarily affected women who came from more favourable backgrounds and who had more schooling. Although controls for maternal childhood characteristics and educational attainment are included in the regression model, there is a concern that the results may be driven by the likely no randomness of women affected by the Marriage Bar. If these women also had "better” parenting skills and married men with "better" parenting skills, then a statistical analysis that does not account for these sources of endogeneity would likely overestimate the effect of the Marriage Bar variable on child outcomes.

To control for these potential sources of endogeneity, regressions are estimated where controls for the sector, social class of the woman's first job and for the years the children's father spent in full-time education are also included. The results are presented in Table 4. All of the estimated models presented in Table 4 control for the maternal background and child characteristics discussed above. The marginal effects for the controls capturing maternal background and child characteristics are not displayed in Table 4 for the sake of brevity. In any case, the estimates are very similar to those in Table 3.

Columns (1) and (2) of Table 4 are the estimated marginal effects when the characteristics of the mother's first job are controlled for. The Marriage Bar was a legal barrier in the public sector, but many private sector companies also operated a Marriage Bar. Women who selected into the public sector, where the Marriage Bar was in place, may have had different parenting skills. In particular, women who chose to be teachers may have had quite different parenting skills than non-teachers. Secondary school 
teachers, the majority of whom worked in the public sector, were not subject to a legally binding Marriage Bar. However, an informal expectation that a married woman would resign may have existed in some schools. Furthermore, the Marriage Bar on primary school teachers was lifted in 1958.

In an attempt to capture these possibly confounding effects, a variable capturing whether the woman's first job was in the public sector is included and a variable that indicates whether she was a teacher. The omitted category for these dummy variables is whether the mother worked in the private sector. Column (1) in Table 4 shows that children of women who worked in the public sector were about 7 percentage points more likely to have completed university than the children of women who worked in the private sector. Furthermore, the children of teachers were 11.3 percentage points more likely to have completed university. Despite controlling for whether the mother was a teacher or whether she worked in the public sector, the children born to a woman affected by the Marriage Bar were still more likely to have completed university. The size of the Marriage Bar marginal effect is, at 6.9 percentage points, only slightly smaller than the estimate presented in Table 3 when the sector of the woman's first job was not controlled for.

Column (2) in Table 4 presents regression estimates that include variables that attempt to control for the social class differences in the woman's first job. The Marriage Bar was not applied to all occupations. Often women in less skilled jobs, such as cleaners, especially in the public sector, were not required to retire when they married. Thus, the estimated Marriage Bar marginal effect could be picking up differences associated with occupation, such as maternal income, which are correlated with child outcomes. In line with the classification proposed by the Irish Central Statistics Office (CSO, 2012), the woman's first job was classified as being: Professional; 
Managerial/Technical; Non-manual; Skilled Manual; Semi-skilled; and Unskilled. The omitted category is whether the woman’s first job was classified as Unskilled Manual.

It is found that the children of women who worked as professionals were nearly 50 percentage points more likely to complete university than the children of women who worked in unskilled positions. The children of women who worked as managers, who worked in other non-manual jobs, or who worked in skilled manual positions were also more likely to earn a degree than the children of women who worked in unskilled manual jobs. Despite controlling for both the sector and the social class of the mother's first job, we still find that the children on women who were directly affected by the Marriage Bar were statistically more likely to have completed university than the children of women not affected by the Marriage Bar. The marginal effects for the Marriage Bar dummy variable in Column (2) of Table 4 is only slightly smaller than it is in Table 3.

In Column (3) of Table 4, a control for the number of years the father of the children spent in full-time education is included. One might be concerned that women who selected into jobs subject to the Marriage Bar were more likely to have married men whose characteristics, such as his parenting ability or his income, were correlated with positive child outcomes. Ideally, one would control for the life-time income of her husband or her husband's income over the course of their children's schooling. Unfortunately, such data is not available. However, the number of years her husband spent in education is likely to be a good proxy variable for his permanent income. It is found that if the husband spent an additional year in education, then the children were about 2.8 percentage points more likely to complete university. It is worth noting that the effects of maternal and paternal education on child outcomes were similar in size. One should note that in the third column of Table 4, the sample size falls considerably 
compared to the first column. The main reason for the decline in the sample size is that women who were widows ( $29 \%$ of the sample), separated (5.4\%) or divorced (3.2\%) at the time of the survey were not asked about their (late/former) husband's education. The remainder did not answer the question about their husband's education.

Although controls for selection into certain occupations and sectors as well as the characteristics of fathers were included, one still might worry that unobserved idiosyncratic differences that are correlated with selection into jobs that were subject to the Marriage Bar as well as child outcomes cause bias in the results. A measure of personality traits of the mother is employed to capture at least some of this idiosyncratic component.

A large literature attests to the power of personality for predicting a whole variety of outcomes including educational and occupational success, lifestyle behaviours, subjective health and wellbeing, success in personal relationships, and physical health and longevity (Bogg and Roberts, 2004; Caspi et al., 2005; Ozer and Benet-Martinez, 2006). Indeed, a recent meta-analysis concluded that personality traits are as powerful a predictor of mortality, divorce and occupational status as socioeconomic status or cognitive ability (Roberts et al., 2007). A key advantage of the TILDA study is that it contains a reliable measure of personality. We therefore controlled for the effect of maternal personality on the child outcomes. Crucially, personality has been found to have substantial heritability (Bouchard and Loehlin, 2001), so it is reasonable to assume that the personality of the mothers is correlated to the personality of their children which in turn might be correlated with the educational outcomes of their children.

Although psychologists continue to debate which personality traits have the greatest importance, consensus is increasing in favour of a five-dimensional model of 
personality structure: Extraversion, Neuroticism, Conscientiousness, Agreeableness and Openness (Caspi et al., 2005). These traits are referred to as the Big-5 personality traits. Briefly, Extraversion indexes a number of traits including warmth, sociability, activity and optimism. Neuroticism reflects a dispositional tendency to experience the world as distressing or threatening and is characterised by anxiety and hostility. Conscientiousness measures self-discipline, orderliness, competence, and planning. Agreeableness reflects traits including trust, altruism and compliance. Finally, Openness reflects a number of traits including intellectual curiosity, imagination and enjoyment of novelty. Openness has been found to correlate highly with intelligence (McCrae and Costa, 1997). In TILDA, the Big-5 personality traits are measured using the 60-item NEO Five-Factor Inventory-3 (Costa and McCrae, 2004). A total of 12 items are used to measure each trait, with the final score ranging between zero and 48 for each trait.

Column (4) in Table 4 shows that, despite also controlling for the Big-5 personality traits, it is still found that the children of women affected by the Marriage Bar were about 6.3 percentage points more likely to complete university than the children of women not affected by the Marriage Bar. In the regression corresponding to the final column of Table 4, the sample size is nearly half that used in the main analysis. The response rate to the personality questions was much lower because the personality questionnaire was given to the respondent to complete and return in their own time whereas the main TILDA questionnaire was applied by an interviewer in a face to face interview.

\section{Conclusion}


The aim of this paper was to empirically examine the relationship between maternal employment and child outcomes with Irish data. The child outcome considered was educational attainment, measured in terms of whether the child completed university education. Regression was used to compare the educational attainment of children of mothers who were required to leave employment on marriage because of the Marriage Bar to the educational attainment of children of mothers who were not required to do so. We believe that this comparison is particularly insightful since the Marriage Bar generates exogenous variation in maternal employment, with the majority of women who left employment because of the Marriage Bar never returning to employment or returning only after several years. Therefore, the presence of the Marriage Bar generated large differences in maternal employment that would not have existed in its absence.

Children of mothers who were "forced" by the Marriage Bar to leave employment have much a higher probability of completing university education that the children of mothers who were not. The difference is around seven percentage points. This is a sizeable effect when compared to the observation that about $40 \%$ of the children in our sample completed university education. This effect was found to be robust to alternative specifications that included variables aimed at controlling for occupation differences, personality traits and husband's education. It is unlikely that the difference between these two groups is a product of specification error in the sense that it is a statistical artefact resulting from key variables not be included in the regressions. 


\section{References}

Baker, Michael, and Kevin Milligan. 2010. "Evidence from Maternity Leave Expansions of the Impact of Maternal Care on Early Child Development.” Journal of Human Resources 45 (4): 1-32.

Baker, Michael, and Kevin Milligan. 2015. “Maternity Leave and Children’s Cognitive and Behavioural Development.” Journal Population of Economics 28: 373-391.

Baum, Charles. 2003. “Does Early Maternal Employment Harm Child Development? An Analysis of the Potential Benefits of Leave Taking.” Journal of Labor Economics 21 (2): 409-448.

Berger, Lawrence, Jennifer Hill, and Jane Waldfogel. 2005. “Maternity Leave, Early Maternal Employment and Child Health and Development in the US.” Economic Journal 115: F29-F47.

Bettinger, Eric, Torjorn Haegeland, and Mari Rege. 2014. “Home with Mom: The Effects of Stay-at-Home Parents on Children's Long-Run Educational Outcomes.” Journal of Labor Economics 32 (3): 443-467.

Bouchard, Thomas. J. Jr., and John C. Loehlin. 2001. "Genes, Evolution, and Personality.” Behavior Genetics 31 (3): 243-273. 
Brunello, Giorgio, Guglielmo Weber, and Christoph T. Weiss. 2017. “Books Are Forever: Early Life Conditions and Lifetime Earnings in Europe.” Economic Journal 127: 271-296.

Carneiro, Pedro, Katrine Loken, and Kjell Salvanes. 2011. “A Flying Start? Maternity Benefits and Long-Run Outcomes of Children.” Journal of Political Economy 123 (2): 365-412.

Caspi, Avshalom, Brent W. Roberts, and Rebecca. L. Shiner. 2005. “Personality Development: Stability and Change.” Annual Review of Psychology 56: 453-484.

Central Statistics Office (CSO). 1971. Report on Vital Statistics. The Stationery Office, Dublin, Ireland.

Central Statistics Office (CSO). 2012. This is Ireland. Highlights from Census 2011, Part 2. Stationery Office, Dublin, Ireland.

Commission on the Status of Women. 1972. Report to Minister of Finance. Stationary Office.

Costa, Paul. T Jr, and Robert R. McCrae. 2004. “A Contemplated Revision of the NEO Five Factor Inventory.” Personality and Individual Difference 36 (3): 587-596. 
Cronin, Hilary, Claire O’Regan, Patricia Kearney, Ciaran Finucane, and Rose Anne Kenny. 2013. "Health and Ageing: Development of the TILDA Health Assessment.” Journal of American Geriatrics Society 61 (s2): S269-S278.

Cullen Owens, Rosemary, 2005. A Social History of Women in Ireland. Dublin: Gill \& Macmillan.

Dahl, Gordon, Katrine Loken, Magne Mogstad, and Kari Vea Salvanes. 2016. "What is the Case for Paid Maternity Leave?” The Review of Economics and Statistics 98 (4): 655-670.

Danzer, Natalia, and Victor Lavy. 2016. “Paid Parental Leave and Children’s Schooling Outcomes.” Economic Journal forthcoming

Denny, Kevin. (2014). “The effect of abolishing university tuition costs: Evidence from Ireland”. Labour Economics 26: 26-33.

Dustmann, Christian, and Uta Schonberg. 2012. "Expansions in Maternity Leave Coverage and Children's Long-Term Outcomes." American Economic Journal: Applied Economics 4 (3): 190-224. 
Ermisch, John, and Marco Francesconi. 2013. “The Effect of Parental Employment on Child Schooling.” Journal of Applied Econometrics 28: 796-822.

James-Burdumy, Susanne. 2005. “The Effect of Maternal Labor Force Participation on Child Development.” Journal of Labor Economics 23 (1): 177-211.

Kearney Patricia, Hilary Cronin, Claire O'Regan, Yumi Kamiya, George Savva, et al. 2011. "Cohort Profile: the Irish Longitudinal Study on Ageing.” International Journal of Epidemiology 40 (4): 877-884.

Kiely, Elisabeth, and Maire Leane 2012. Irish Women at Work, 1930-1960: An Oral History. Irish Academic Press.

Liu, Qian, and Oskar Nordstrom Skans. 2010. “The Duration of Paid Parental Leave and Children's Scholastic Performance.” B.E. Journal of Economic Analysis and Policy $10(1)$

McCrae, Robert R., and Paul T. Costa Jr .1997. "Conceptions and Correlates of Openness to Experience.” In: Handbook of Personality Psychology, edited by Hogan R, Johnson JA, Briggs SR, 825-847. San Diego: Academic Press, Inc.

OECD, (2016). Education at a Glance 2016: OECD Indicators, OECD Publishing, Paris. http://dx.doi.org/10.187/eag-2016-en 
Pyle, Jean Larson. 1990. The State and Women in the Economy: Lessons from Sex Discrimination in the Republic of Ireland. Albany, New York: State University of New York Press.

Rasmussen, Astrid Wurtz. 2010. “Increasing the Length of Parents’ Birth-Related Leave: The Effect on Children's Long-Term Educational Outcomes.” Labour Economics 17: 91-100.

Ruhm, Christopher J. 2004. “Parental Employment and Child Cognitive Development.” The Journal of Human Resources 39 (1): 155-192.

Ruhm, Christopher J. 2008. “Maternal Employment and Adolescent Development.” Labour Economics 15: 958-983.

Schildberg-Hoerisch, Hannah. 2011. Does Parental Employment Affect Children’s Educational Attainment?” Economics of Education Review, 30: 1456- 1467.

Waldfogel, Jane, Wen-Jui Han, and Jeanne Brooks-Gunn. 2002. “The Effects of Early Maternal Employment on Child Cognitive Development.” Demography, 39 (2): 369392. 
Whelan, Brendan, and George Savva. 2013. "Design and Methodology of the TILDA Study.” Journal of American Geriatrics Society 61 (s2): S265-S268. 
Table 1

Summary Statistics of Variables Capturing Maternal Labour Market Attachment

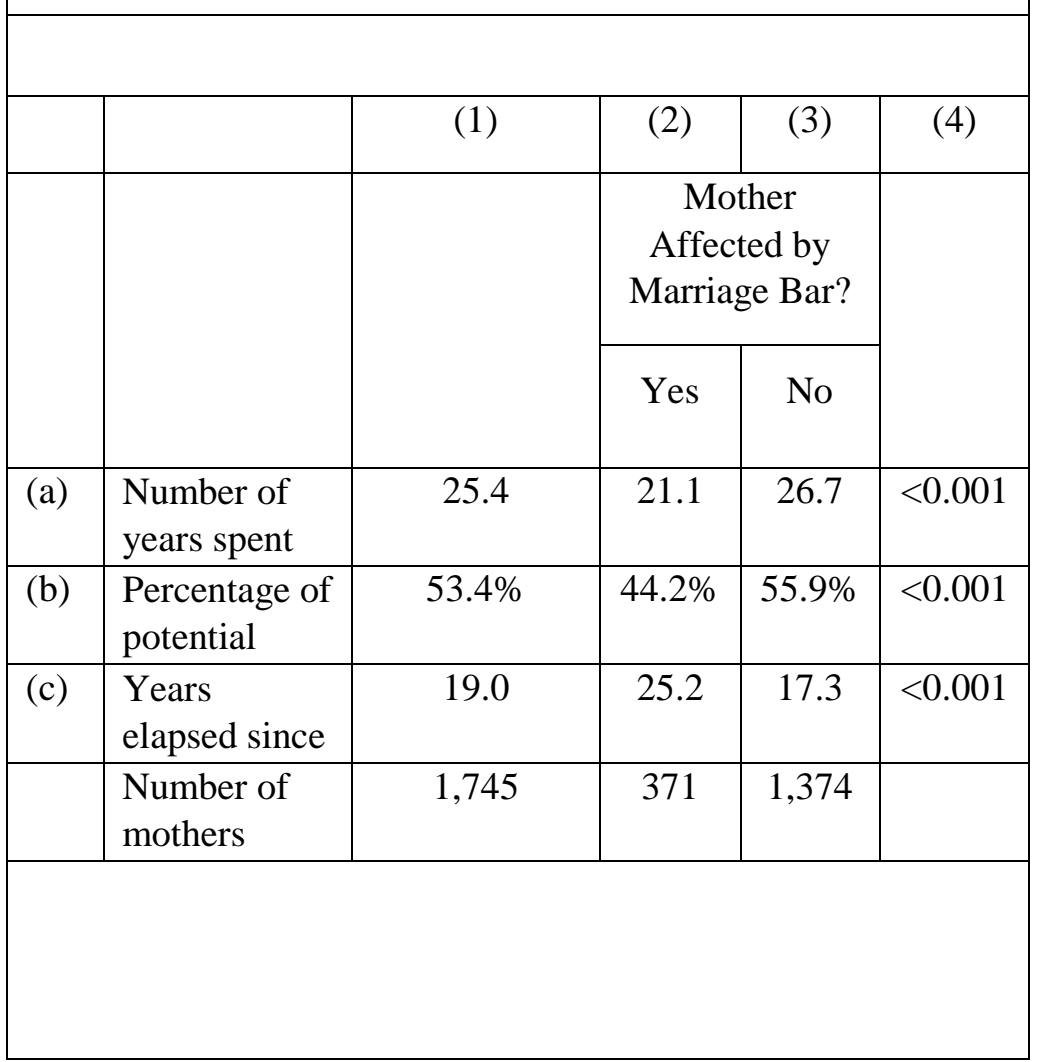


Table 2

Summary Statistics of Variables Employed in the Regression Models

\begin{tabular}{|c|c|c|c|c|}
\hline & \multirow[t]{3}{*}{ (1) } & (2) & (3) & \multirow[t]{3}{*}{ (4) } \\
\hline & & \multicolumn{2}{|c|}{$\begin{array}{c}\text { Mother Affected by Marriage } \\
\text { Bar? }\end{array}$} & \\
\hline & & Yes & No & \\
\hline \multicolumn{5}{|l|}{ Variable } \\
\hline \multicolumn{5}{|l|}{ Outcome variable } \\
\hline Child completed university & $38.5 \%$ & $47.1 \%$ & $35.9 \%$ & $<0.01$ \\
\hline \multicolumn{5}{|l|}{ Mother's Characteristics } \\
\hline Year of birth & 1943 & 1940 & 1944 & $<0.01$ \\
\hline Poor family during childhood & $19.0 \%$ & $12.3 \%$ & $20.8 \%$ & $<0.01$ \\
\hline Poor health during childhood & $7.1 \%$ & $6.2 \%$ & $7.3 \%$ & 0.351 \\
\hline Recalls books in childhood & $55.5 \%$ & $60.8 \%$ & $54.1 \%$ & 0.026 \\
\hline Grew up in rural area & $56.3 \%$ & $50.4 \%$ & $57.8 \%$ & 0.016 \\
\hline Number of siblings & 5.2 & 5.1 & 5.2 & 0.403 \\
\hline Own mother worked & $26.6 \%$ & $20.6 \%$ & $28.2 \%$ & 0.009 \\
\hline Own father worked & $92.8 \%$ & $94.7 \%$ & $92.3 \%$ & 0.166 \\
\hline Years of schooling & 11.1 & 11.7 & 11.0 & $<0.01$ \\
\hline Age at first birth & 26.3 & 26.8 & 26.2 & 0.059 \\
\hline Number of children & 3.6 & 4.0 & 3.5 & $<0.01$ \\
\hline \multicolumn{5}{|l|}{ Child's characteristics } \\
\hline Year of birth & 1973 & 1970 & 1973 & $<0.01$ \\
\hline Female & $49.3 \%$ & $51.2 \%$ & $48.8 \%$ & 0.144 \\
\hline Number of mothers & 1,745 & 371 & 1,374 & \\
\hline Number of children & 6,241 & 1,474 & 4,767 & \\
\hline
\end{tabular}

Notes: The outcome variable and child's characteristics are presented at child's level. Mother's characteristics are presented at mother's level. 


\begin{tabular}{|c|c|}
\hline \multicolumn{2}{|c|}{$\begin{array}{c}\text { Table } 3 \\
\text { Marginal Effects of the Probability of Child Completing University }\end{array}$} \\
\hline & (1) \\
\hline \multicolumn{2}{|l|}{ Variable } \\
\hline \multirow{2}{*}{ Marriage Bar } & $0.079 * * *$ \\
\hline & $(0.020)$ \\
\hline \multicolumn{2}{|l|}{ Mother's Characteristics } \\
\hline \multirow[t]{2}{*}{ Year of Birth } & 0.002 \\
\hline & $(0.002)$ \\
\hline \multirow[t]{2}{*}{ Poor family during childhood } & -0.025 \\
\hline & $(0.023)$ \\
\hline \multirow{2}{*}{ Poor health during childhood } & 0.022 \\
\hline & $(0.033)$ \\
\hline \multirow[t]{2}{*}{ Recalls books in home during childhood } & $0.065^{* * *}$ \\
\hline & $(0.018)$ \\
\hline \multirow[t]{2}{*}{ Grew up in rural area } & 0.015 \\
\hline & $(0.018)$ \\
\hline \multirow[t]{2}{*}{ Number of her siblings } & $-0.006^{*}$ \\
\hline & $(0.003)$ \\
\hline \multirow[t]{2}{*}{ Own mother worked } & -0.002 \\
\hline & $(0.020)$ \\
\hline \multirow[t]{2}{*}{ Own father worked } & 0.044 \\
\hline & $(0.031)$ \\
\hline \multirow{2}{*}{ Years of schooling } & $0.050 * * *$ \\
\hline & $(0.004)$ \\
\hline \multirow[t]{2}{*}{ Age at first birth } & $0.012 * * *$ \\
\hline & $(0.002)$ \\
\hline \multirow[t]{2}{*}{ Number of children } & $-0.023 * * *$ \\
\hline & $(0.005)$ \\
\hline \multicolumn{2}{|l|}{ Child's characteristics } \\
\hline \multirow{2}{*}{ Year of birth } & $0.004 * * *$ \\
\hline & $(0.001)$ \\
\hline \multirow[t]{2}{*}{ Female } & $0.064 * * *$ \\
\hline & $(0.013)$ \\
\hline Observations & 6,241 \\
\hline
\end{tabular}




\begin{tabular}{|c|c|c|c|c|}
\hline \multicolumn{5}{|c|}{$\begin{array}{l}\text { Table } 4 \\
\text { Marginal Effects of the Probability of Child Completing University } \\
\text { Alternative Specifications }\end{array}$} \\
\hline Variable & (1) & $(2)$ & (3) & $(4)$ \\
\hline \multirow[t]{2}{*}{ Marriage Bar } & $0.069 * * *$ & $0.059 * * *$ & $0.063 * *$ & $0.063 * *$ \\
\hline & $(0.020)$ & $(0.020)$ & $(0.026)$ & $(0.027)$ \\
\hline \multicolumn{5}{|l|}{ Mother's sector of first job } \\
\hline \multirow[t]{2}{*}{ Public Sector } & $0.070 * * *$ & $0.063 * *$ & 0.041 & 0.049 \\
\hline & $(0.024)$ & $(0.027)$ & $(0.032)$ & $(0.035)$ \\
\hline \multirow[t]{2}{*}{ Teaching } & $0.113 * *$ & $0.133 * *$ & $0.107 *$ & $0.124^{*}$ \\
\hline & $(0.047)$ & $(0.052)$ & $(0.064)$ & $(0.069)$ \\
\hline \multicolumn{5}{|c|}{ Mother's social class of first job } \\
\hline \multirow[t]{2}{*}{ Professional } & & $0.498 * * *$ & $0.309 * *$ & 0.127 \\
\hline & & $(0.113)$ & $(0.140)$ & $(0.160)$ \\
\hline \multirow[t]{2}{*}{ Managerial \& technical } & & $0.176^{* * *}$ & 0.102 & 0.050 \\
\hline & & $(0.047)$ & $(0.066)$ & $(0.070)$ \\
\hline \multirow[t]{2}{*}{ Non-manual } & & $0.188 * * *$ & $0.095^{*}$ & 0.060 \\
\hline & & $(0.038)$ & $(0.053)$ & $(0.058)$ \\
\hline \multirow[t]{2}{*}{ Skilled manual } & & $0.098 * *$ & 0.041 & 0.037 \\
\hline & & $(0.040)$ & $(0.056)$ & $(0.062)$ \\
\hline \multirow[t]{2}{*}{ Semi-skilled manual } & & 0.051 & -0.002 & -0.042 \\
\hline & & $(0.038)$ & $(0.052)$ & $(0.059)$ \\
\hline \multirow[t]{2}{*}{ Father's years of schooling } & & & $0.028 * * *$ & $0.026 * * *$ \\
\hline & & & $(0.004)$ & $(0.004)$ \\
\hline \multicolumn{5}{|l|}{ Mother's personality } \\
\hline \multirow[t]{2}{*}{ Conscientiousness } & & & & 0.004 \\
\hline & & & & $(0.002)$ \\
\hline \multirow[t]{2}{*}{ Neuroticism } & & & & 0.000 \\
\hline & & & & $(0.002)$ \\
\hline \multirow[t]{2}{*}{ Extraversion } & & & & 0.003 \\
\hline & & & & $(0.002)$ \\
\hline \multirow[t]{2}{*}{ Agreeableness } & & & & -0.002 \\
\hline & & & & $(0.003)$ \\
\hline \multirow[t]{2}{*}{ Openness } & & & & 0.001 \\
\hline & & & & $(0.002)$ \\
\hline Observations & 6,238 & 6,138 & 3,751 & 3,297 \\
\hline \multicolumn{5}{|c|}{$\begin{array}{l}\text { Notes: All of the maternal background and child characteristics shown in Table } 3 \text { are also controlled for in the } \\
\text { estimated models in Table } 4 \text {, but are not displayed for brevity. } \\
\text { Standard errors in parentheses: }{ }^{*} \mathrm{p}<0.10,{ }^{* *} \mathrm{p}<0.05,{ }^{* * *} \mathrm{p}<0.01 \text {. Standard errors are clustered at family level. }\end{array}$} \\
\hline
\end{tabular}


Figure 1: Percent Ever/Never Worked for Pay by Birth Cohort, Irish Women

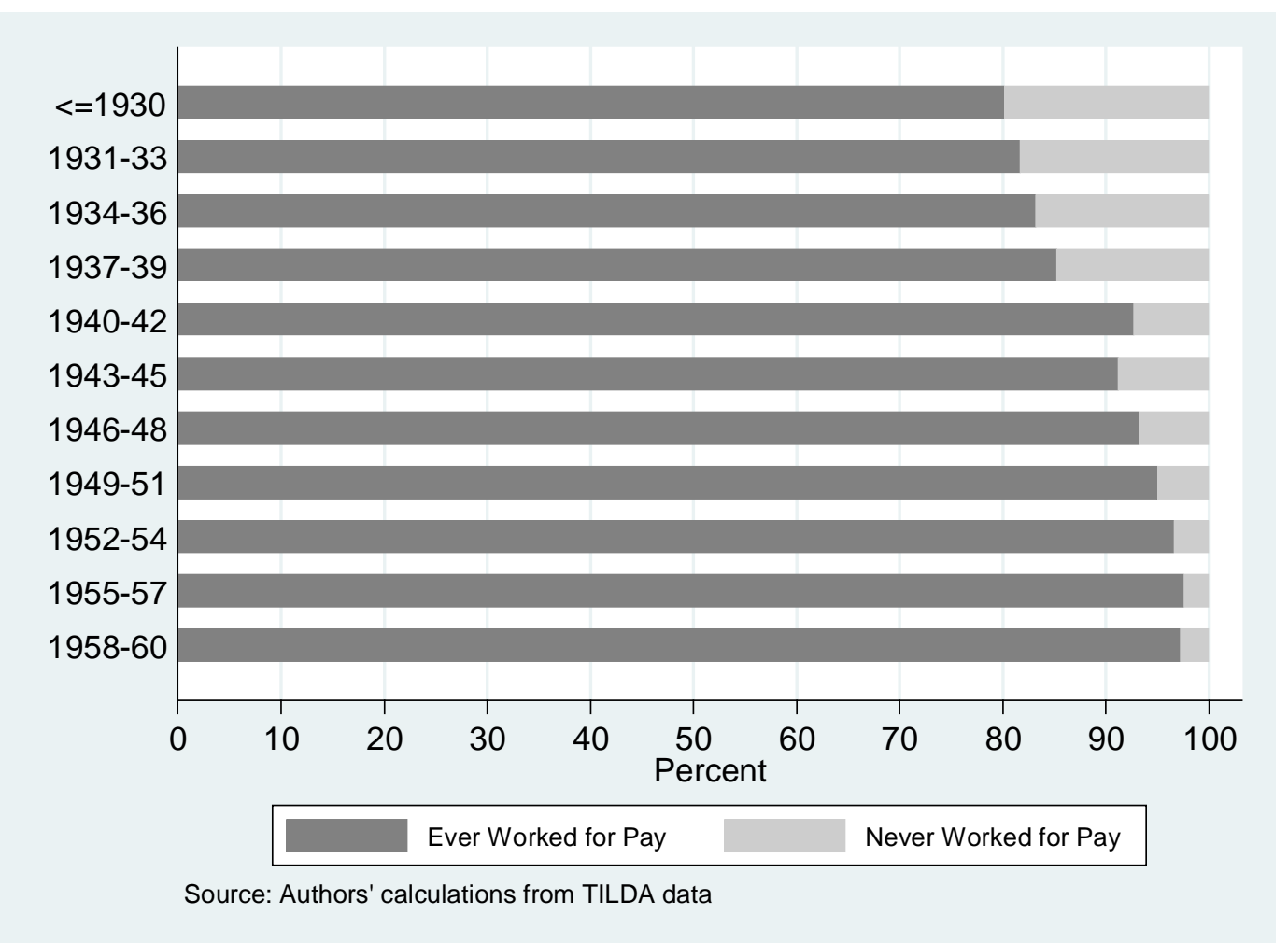


Figure 2: Percent of Never/Ever Married Women by Birth Cohort, Various

\section{Countries}

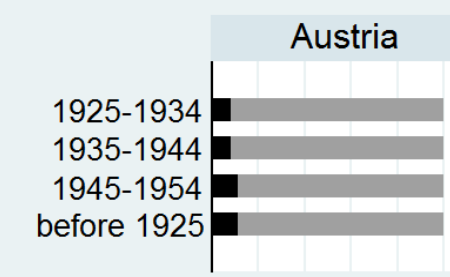

Germany
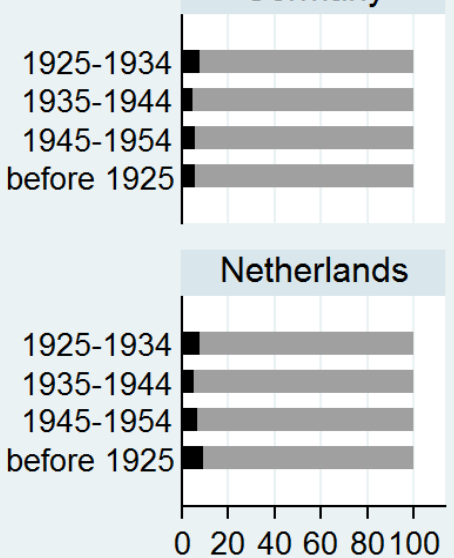

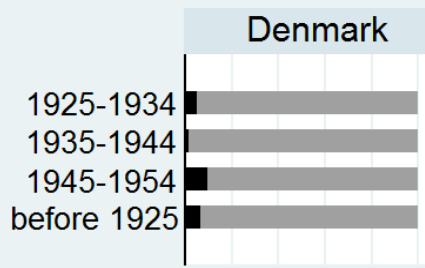

Greece

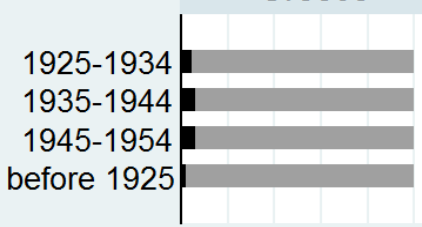

Spain

1925-1934 1935-1944 $1945-1954$ before 1925

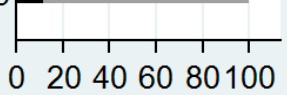

France

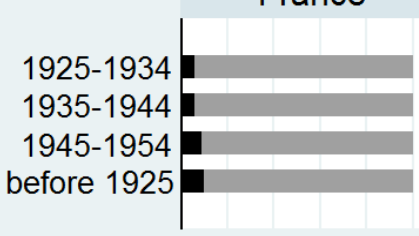

IRELAND

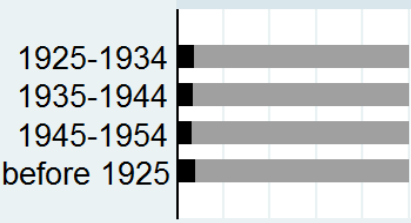

Sweden

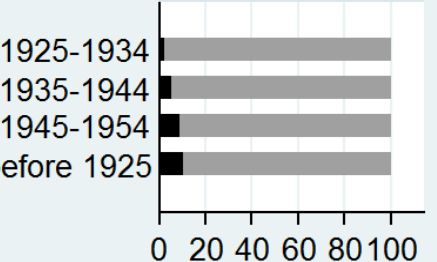

$\%$ Never Married

$\%$ Married

Authors' calculations from SHARE \& TILDA 
Figure 3: Percent of Ever/Never Married by Birth Cohort, Irish Women

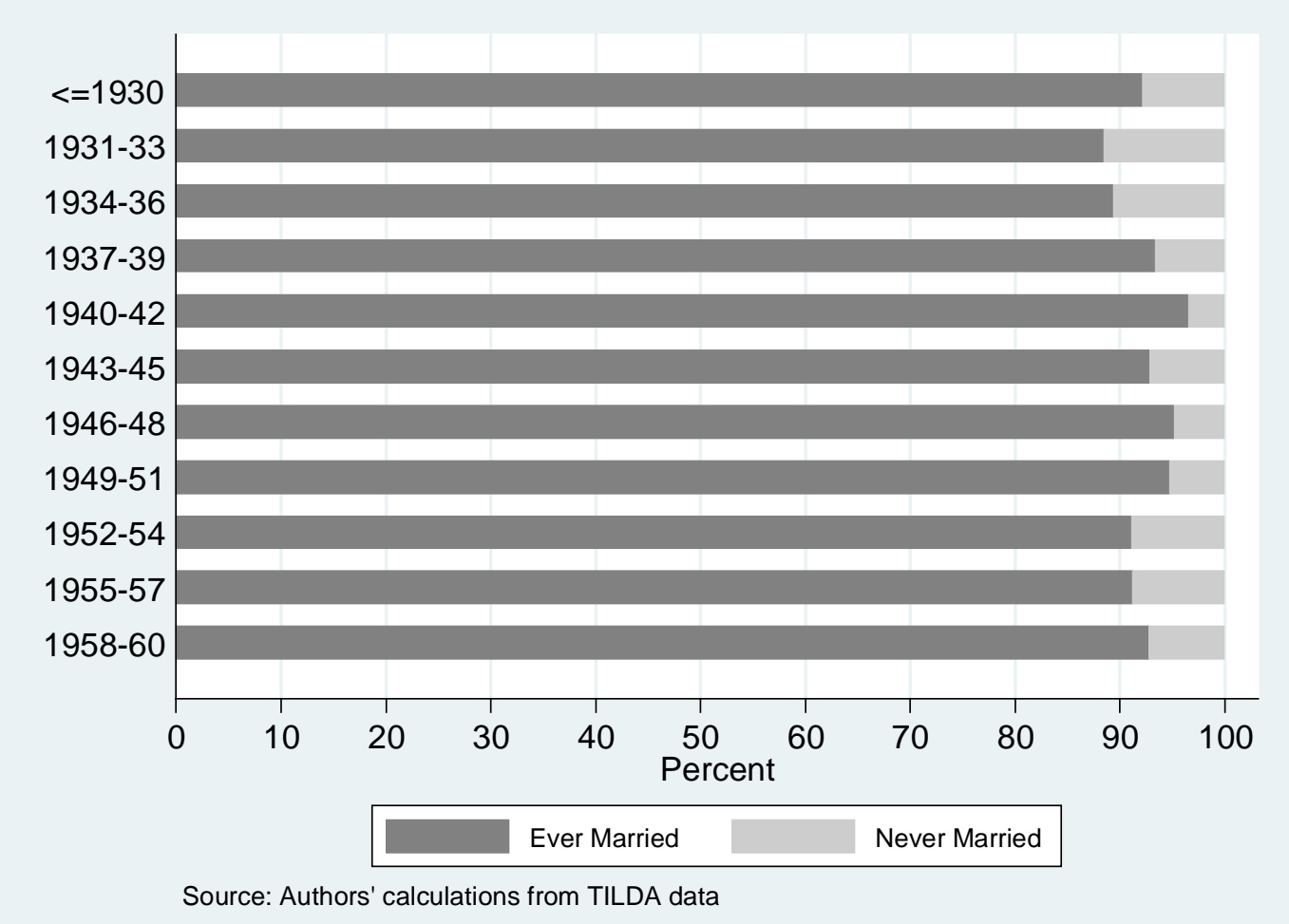


Figure 4: Percent Had Children and Childless by Birth Cohort, Irish Women

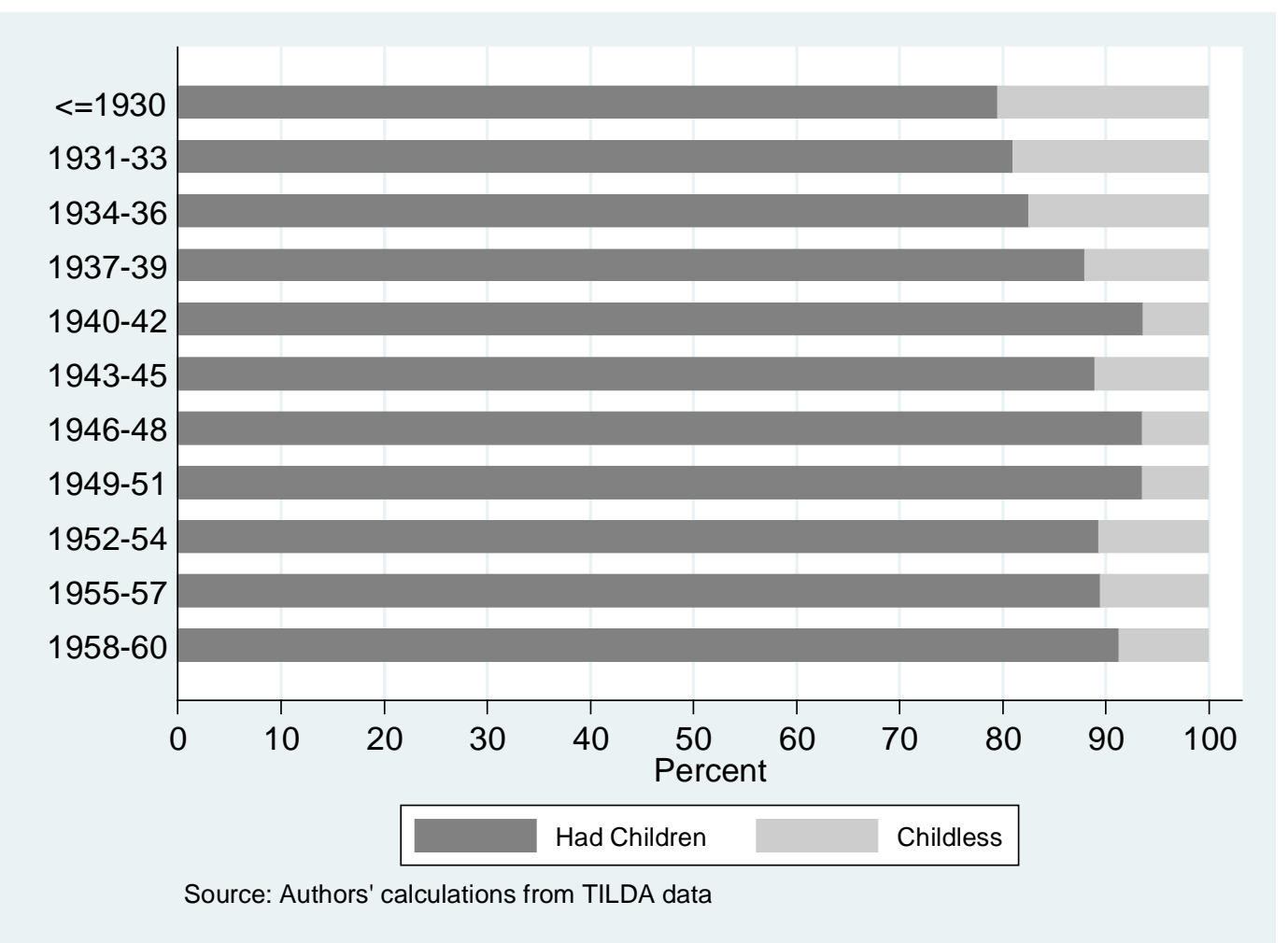


Figure 5: Average Number of Children (if Had Children) by Birth Cohort, Irish Women

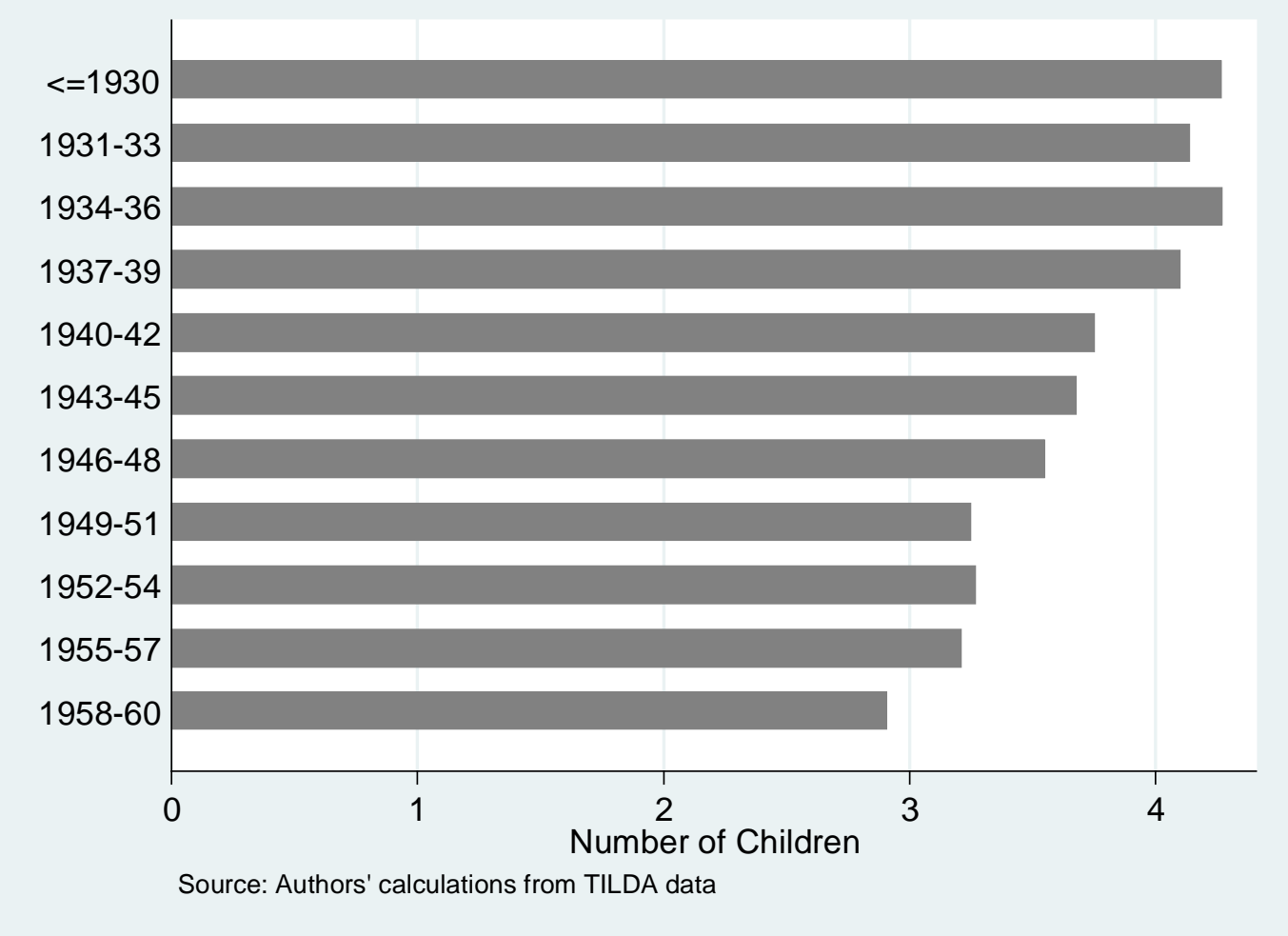

